\title{
Luck, propositional perception, and the Entailment Thesis
}

\author{
Chris Ranalli
}

Received: 19 April 2013 / Accepted: 23 July 2013 / Published online: 15 August 2013

(C) Springer Science+Business Media Dordrecht 2013

\begin{abstract}
Looking out the window, I see that it's raining outside. Do I know that it's raining outside? According to proponents of the Entailment Thesis, I do. If I see that $\mathrm{p}$, I know that p. In general, the Entailment Thesis is the thesis that if S perceives that p, S knows that p. But recently, some philosophers (McDowell, in Smith (ed.) Reading McDowell on mind and world, 2002; Turri, Theoria 76(3):197-206, 2010; Pritchard, Philos Issues (Supplement to Nous) 21:434-455, 2011; Pritchard, Epistemological disjunctivism, 2012) have argued that the Entailment Thesis is false. On their view, we can see $\mathrm{p}$ and not know that $\mathrm{p}$. In this paper, I argue that their arguments are unsuccessful.
\end{abstract}

Keywords Entailment Thesis - Belief · Luck · Propositional perception ·

Barn-cases · Knowledge

\section{Introduction}

I look out the window, and I see that it's raining outside. Do I now know that it's raining outside? According to proponents of the Entailment Thesis, I do (Williamson 2000; Stroud 2009, 2011; Cassam 2007a,b, 2008; Peacocke 2005; Dretske 1969). If I see that $\mathrm{p}$, I know that $\mathrm{p}$. In general, the Entailment Thesis is the thesis that if $\mathrm{S}$ perceives that $\mathrm{p}$, then $\mathrm{S}$ knows that $\mathrm{p}$. There are no cases where one succeeds in perceiving that something is so but fails to know that it is so. Of course, one could be a proponent of specific entailment theses for specific perceptual modalities without accepting the general Entailment Thesis, but I'm going to presume throughout that arguments we

C. Ranalli $(\otimes)$

School of Philosophy, Psychology and Language Sciences, The University of Edinburgh,

Dugald Stewart Building, 3 Charles Street, EH8 9AD Edinburgh, UK

e-mail: c.ranalli@sms.ed.ac.uk 
consider for and against it are applicable mutatis mutandis to more specific versions of the Entailment Thesis.

So, what might lead one to accept the Entailment Thesis? Perhaps what makes the Entailment Thesis look plausible is just that it is intuitive. After all, it sounds absurd to claim 'I see that it's raining outside, but I don't know that it is', and perhaps what explains it sounding absurd is that it is absurd. The guiding intuition here is that what best explains the seeming contradiction is that we are expressing a genuine contradiction. ${ }^{1}$

Moreover, there is a plausible semantics of perception-verbs in propositional contexts, which seems to have the consequence that the Entailment Thesis is true. If this is right, then the Entailment Thesis just falls out of a plausible semantics for perceptionverbs in those contexts. For example, Gisborne (2010) and French (2012) argue that there are certain senses of 'see' in ascriptions of 'S sees that p' which are knowledgeascribing. If this is right, then it is hard to see how an Entailment Thesis is not true of those senses of 'see' when it is embedded in sentences of the form ' $S$ sees that $p$ '.

We might also appeal to the pragmatics of our explanations of knowledge. For example, a good explanation of how I know that it's raining outside, if I'm just watching the rain pouring down from the window, is that I just see that it's raining outside. According to Cassam, these sorts of explanations of how I know that something is so "have a kind of finality that many other explanations lack" and "[...] are not open to the same [kinds of] challenges" that other explanations of how I know something might be open to (2007a, p. 334). For example, if I ask 'how does S know that p?', and I'm told 'S read that p', it makes sense to ask 'but does S really know that p?'. However, if the response had been ' $S$ saw that p', it doesn't make sense to ask 'but does S really know that p?'. Why? According to Cassam, the reason is that, while the former statement is open to further challenge, "there is no room for further challenge" of the latter statement "unless this is a way of questioning whether you really see that p" (my emphasis; 2007a, p. 334). ${ }^{2}$ Extending this idea, we might think that what best explains this pragmatic phenomena is the truth of the Entailment Thesis.

1 Cf. Unger (1972, pp. 304-305) for this suggestion. But there is a problem for this suggestion. Consider, objectual-perception reports, as in the first conjunct of (1) 'S sees the bus stopping, but doesn't know that the bus is stopping'. (1) sounds just as absurd as (2) 'S sees that the bus is stopping, but doesn't know that the bus is stopping'. But, plausibly, there is no entailment from ' $\mathrm{S}$ sees an $x$ which is $F$ ' to 'S knows that $x$ is $F$ '. This result seems to undercut the idea that the Entailment Thesis is what best explains the seeming inconsistency of (2). Dretske (1969) provides a pragmatic explanation for the seeming inconsistency of reports like (1), rather than a semantic explanation (which would appeal to considerations like the Entailment Thesis), and one might think that this kind of explanation can be extended to reports like (2), although it's not clear that it will work. Thanks to Craig French for pointing this out to me.

2 Consider two views about visual propositional perception: (WK) 'seeing that $p$ is a way of knowing that p' and (EWK) 'seeing that $p$ is a particularly exemplary way of knowing that $p$ '. Notice that it seems possible for (WK) to be true without (EWK) being true. How? First consider this question: what makes a way of knowing that $p$ a particularly exemplary way of knowing that $p$ ? One condition might be that that way of knowing that $p$ actually implies that the agent knows that $p$. So, for example, we could explain the truth of (EWK) in terms of the Entailment Thesis, even though the truth of the Entailment Thesis might not explain the truth of (WK). For example, consider (RWK): 'reading that $p$ is a way of knowing that p'. Plausibly, we may think that one can read, in a reliable newspaper, say, that a building was just demolished, and 
But what turns on the truth of the Entailment Thesis? On the one hand, we might think that there is an intimate relationship between perception and knowledge which has the Entailment Thesis as a consequence. One relationship might be that we cannot understand the former without reference to the later: we cannot understand what it is to perceive that $\mathrm{p}$ without reference to what it is to know that $\mathrm{p} .^{3}$ As Cassam (2007a) highlights "[i]f perceiving that $\mathrm{P}$ is a form of knowing that $\mathrm{P}$ then it is easy to see why we could not explain all the features of the concept of perception without reference to the concept of knowledge" (Cassam 2007a, p. 38). So on this kind of account, the Entailment Thesis would be a consequence of our conceptual analysis of propositional perception.

A related idea is expressed in Williamson (2000). One of his central aims there is to provide a non-reductive account of propositional knowledge. In particular, he maintains that "knowing is the most general stative propositional attitude such that, for all propositions where $p$, necessarily if one has it to $p$ then $p$ is true" (Williamson 2000, p. 39). So if seeing that $\mathrm{p}$ is a particular factive statitive attitude, Williamson's account has the consequence that seeing that $\mathrm{p}$ entails knowing that $\mathrm{p}$. So in order to maintain

\section{Footnote 2 continued}

thereby come to know that the building was just demolished. But reading that $p$ doesn't seem to imply knowing that $p$. After all, we can read that $p$ even if $p$ is false. I can read that a certain election was rigged even if this isn't true; perhaps the journalist was mislead, and given false information. Insofar as knowledge is factive, then, it is at least possible for reading that $p$ to be a way of knowing that $p$ without entailing that whenever $\mathrm{S}$ reads that $p, \mathrm{~S}$ knows that $p$. How does this consideration relate to the passage from Cassam? First, we might think that (EWK) provides support for the Entailment Thesis, even if (WK) doesn't. On this score, I am appealing to the relevant passage from Cassam (2007a, pp. 343-344) in order to highlight a prima facie motivation for endorsing the Entailment Thesis. But whether this reason can be sustained under scrutiny is open to dispute, and we can see this by looking to some of the other things that Cassam says. For example, it's not clear that Cassam would endorse the prima facie motivation that I presented in the main body of the text. Here's why: according to Cassam, $\phi$-ing that $p$ can be a way of knowing that $p$ even if ' $\mathrm{S}$ $\phi$-ed that $p$ ' doesn't entail 'S knows that $p$ '. Of course, Cassam could maintain that for $\phi$-ing that $p$ to be an exemplary way of knowing that $p$ it must entail knowledge. But it is not obvious that Cassam does think this. See his (2007a, pp. 345-347) for some discussion on this issue. Moreover, Cassam also seems to hold that explanations of how someone knows that $p$ in terms of objectual perception (e.g., seeing an object $o$ which is $F$; seeing a red tomato) can, in certain sorts of cases, be exemplary explanations of how someone knows that $p$ in at least something like the way in which explanations of how someone knows that $p$ in terms of seeing that $p$ are exemplary. See Cassam (2008, pp. 39-41) in particular. So Cassam does not appear to maintain that just because certain explanations of how someone knows that $p$ might be particularly exemplary, such as explanations in terms of propositional perception or objectual perception, the exemplariness of the explanation needs to be explained by appeal to the Entailment Thesis. Furthermore, if it is true that explanations of how someone knows that $p$ in terms of objectual perception can be exemplary explanations, one might then want to reassess the motivating consideration I highlighted in the main body of the text. After all, if they can be exemplary without being knowledge-entailing, this will be a problem for appealing to the exemplariness of explanations of how someone knows that $p$ in terms of propositional perception being grounded in the Entailment Thesis. This all requires further discussion, but for my purposes I can set it aside, since I only want to highlight some prima facie considerations which motivate the Entailment Thesis. I have used (Cassam 2007a, 2008) to serve that purpose. But how one ought to read Cassam's own commitments, and whether those motivating considerations provide adequate support for the Entailment Thesis, are further matters. For theoretical considerations in favor of the Entailment Thesis, see Cassam (2007b), Williamson (2000), Stroud (2002, 2009, 2011), Unger (1972), and Dretske (1969).

3 For example, Strawson $(1992,1995)$ suggests that we cannot understand the concept of perception without reference to the concept of knowledge, and vice-versa. 
Williamson's non-reductive account of knowledge, it seems as if the Entailment Thesis must be true.

A final source of interest comes from concerns with skepticism. According to Stroud $(2009,2011)$, the possibility of propositional perception-perceiving that $\mathrm{p}$ - is central to avoiding skepticism. On his view, if we want to understand "how our knowledge of the world is possible we cannot settle for less than our being able sometimes simply to see or in general to perceive that such-and-such is so in the world we take ourselves to know about" (Stroud 2009, pp. 564-565). But in order to make room for this view, we have to "abandon the idea of purely sensory knowledge that is neutral with respect to how things are in an independent world" - that is, we have to make room for the idea that "[propositional perception is] a way of knowing" about the world around us" (Stroud 2009, pp. 565-566). ${ }^{4}$

But despite its intuitive and theoretical appeal, there have been a number of powerful arguments against it (McDowell 2002; Turri 2010; Pritchard 2011, 2012). In this paper, I group them into three general kinds of argument. One argument proceeds from the premise, a la Gettier, that knowledge excludes luck, and the premise that propositional perception does not exclude luck, to the conclusion that one can see that $\mathrm{p}$ but not know that p. Call this the Argument from Luck. In $\S$. 2, I argue that the Argument from Luck is not sound and therefore poses no threat to the Entailment Thesis. The second argument proceeds from the premise that we can see that $\mathrm{p}$ even if there are known defeaters to $\mathrm{p}$; and if there are known defeaters to $\mathrm{p}$, then we ought not believe that $\mathrm{p}$. But if we know that $\mathrm{p}$, then we ought to believe that $\mathrm{p}$. Thus, we can see that $\mathrm{p}$ but not know that $\mathrm{p}$. Call this the Argument from Defeat. In $\S$. 3, I argue that this argument is either unsound or else relies on a crucial assumption which forms the basis of our third argument against the Entailment Thesis. The third and perhaps more powerful argument against the Entailment Thesis moves from the premise that knowledge entails belief, and the premise that we can see that $\mathrm{p}$ without believing that $\mathrm{p}$, to the conclusion that we can see that $\mathrm{p}$ without knowing that $\mathrm{p}$. Call this the Argument from Belief. In $\S .4$, I argue that the proponent of the Entailment Thesis can provide at least three diagnoses of where this argument fails.

\section{The argument from luck}

It is a platitude about propositional knowledge that it excludes epistemic luck. Often, this claim is put forward as an intuition which explains other, perhaps even more basic, epistemological intuitions. The intuition can be expressed along the following lines. Knowledge is a kind of achievement. But if one gets things right because of some imposition of luck - an imposition which luckily gave her a true, rather than a false belief, say - then it cannot also be the case that it was an achievement, something for which the agent can take credit. The intuition here is just that genuine achievements

\footnotetext{
4 Stroud (2011) registers this idea in the first three paragraphs of that paper, building on from his (2009) work on skepticism about perceptual knowledge of the world. Moreover, although Stroud's reasons are different from Dretske's, Dretske expresses a similar idea in his (2010) contribution to A Companion to Epistemology (2nd ed). For a discussion on how theories of propositional perception make contact with skepticism, see Cassam (2007b(Chap. 1), 2009), McDowell (1994, 2008), and Stroud (2011).
} 
exclude success by luck, and knowledge is some such achievement. ${ }^{5}$ Likewise, in the Gettier counter-examples (1963), it seems like although the agent formed a true justified belief, the agent nevertheless did not have knowledge. And what seems to explain her lack of knowledge is that she got things right rather than wrong because of luck. Indeed, we might just think that this was the point of the Gettier counterexamples: to expose that what was wrong with the tripartite definition of knowledge is that it did not exclude luck. ${ }^{6}$

Now consider the Entailment Thesis. We can ask whether or not seeing or otherwise perceiving that $\mathrm{p}$ entails that we haven't luckily gotten a true belief. If knowledge excludes luck, and a state $\phi$ entails that $S$ knows that $p, \phi$ excludes luck as well. For if one can see that $\mathrm{p}$ but nevertheless get a true belief because of luck, then seeing that $\mathrm{p}$ could not entail that one knows that $\mathrm{p}$. So now consider a case where it looks like we can see that $\mathrm{p}$ and believe truly that $\mathrm{p}$ because of some imposition of luck:

Out in a field, Smith and Jones are walking around what look like a hundred or so barns. Smith, some twenty-meters in front of Jones, stops in front of a particular barn and looks at it. He thinks to himself 'look at how bright this barn is'. Jones catches up, but a bug has become lodged in his eye. He looks at the barn, but doesn't recognize it as such. He asks 'is that a barn or what?'. Smith replies, 'yes, I can see that it is'. Unbeknownst to Smith and Jones, however, that is the one barn among hundreds of fake barns made to look just like barns.

Call this case BARN after Goldman (1976) barn-façade case. What should we draw from BARN? Consider the following argument:

(1) Smith sees that it is a barn.

This premise is intuitively plausible. After all, Smith is looking at a real barn, he applies the concept $<$ barn $>$ to the barn in front of him, the weather is clear, and his perceptual faculties are working fine. We have no prima facie reason not to think that he sees that it's a barn. Together with the Entailment Thesis, (1) implies:

(2) Smith knows that it is barn.

But this doesn't seem right. For this case looks like nothing more than a standard barncase, where the intuition is that the subject does not know that it is a barn. Indeed, had Smith come upon one of those fake barns - something that could very easily have happened, to be sure- he would have mistaken it for a barn. So, it seems like Smith's getting a true belief rather than a false belief was due in part to luck. But knowledge excludes luck. So:

(3) Smith does not know that it is a barn.

\footnotetext{
5 Several epistemologists (Sosa 2007; Greco 2003; Pritchard 2005) think that the anti-luck intuition on knowledge is grounded in some such intuition about how knowledge is a kind of achievement. Cf. Prichard (2007, p. 277) for a detailed expression of this intuition.

6 Cf. Dancy (1985, p. 134): "[J]ustification and knowledge must somehow not depend on coincidence or luck. This was just the point of the Gettier counterexamples; nothing in the tripartite definition excluded knowledge by luck". See also Pritchard (2013), where he argues against some recent attempts to show that knowledge is compatible with epistemic luck.
} 
Contradiction. Now, how should we resolve this puzzle? We have at least three options. The first option would be to maintain the Entailment Thesis and the antiluck condition on knowledge, but deny that Smith sees that a barn is there. Call this the Straightforward Response. The second option would be to maintain the anti-luck condition, but also maintain that Smith sees that a barn is there. This leaves us with two further options. The first option is negative. If BARN is a case where luck prevents the agent from knowing that a barn is there, then we should reject the Entailment Thesis. Call this the Negative Response. However, if BARN is not a case where luck prevents the agent from knowing that a barn is there, then it is still open for one to maintain the anti-luck condition on knowledge, and just insist that, in this case and others like it, because the agent sees that a barn is there, they know that a barn is there as well. Call this the Positive Response. Of course, the burden is on the proponent of the Positive Response to explain how what looks like a standard barn case is in fact not a standard barn case. In what follows, I'll present an argument for the Positive Response, and explain how the verdict in this case doesn't conflict with our intuitions about barn-cases.

Consider first the Straightforward Response. ${ }^{7}$ This might look like the most natural response for the proponent of the Entailment Thesis. After all, if the Entailment Thesis is true, then if Smith sees that a barn is there, he knows that a barn is there. But since he does not know that a barn is there, it follows that he does not see that it is there either. ${ }^{8}$ While this response might look plausible, the proponent of the Entailment Thesis is not confined to this response. On this score, the proponent of the Entailment Thesis might think that the Straightforward response trades on the idea that what explains Smith's not seeing that a barn is there is the truth of the Entailment Thesis plus his not knowing that a barn is there. But now the following question arises: how are we to explain his not seeing that a barn is there together with the fact that he sees a barn, applied the concept <barn > to a barn, is competent with that concept, and his perceptual faculties are working fine, in otherwise good conditions? The point here is

\footnotetext{
7 Both Millar (2008) and Cassam (2008) advance this kind of response. Their motivation is not to preserve the Entailment Thesis per se, however, since their motivation is just to describe the relationship between visual perception and knowledge, where a consequence is the truth of the Entailment Thesis. For Millar at least, environments with multiple ringers prevents one from exercising their relevant "recognitional capacities" and it's this which prevents the agent in barn-type cases from seeing that a barn is in front of them. Cassam, on the other hand, just seems to maintain that it's because S can't know in barn-type cases which prevents $\mathrm{S}$ from seeing that a barn is there as well, given that seeing that $\mathrm{p}$ is a way of coming to know that p. See Millar (2008, pp. 333-337), and Cassam (2008, pp. 38-41), in particular.

8 For an interesting discussion on different theories of propositional perception and their relation to perceptual experience, see French (2013). Moreover, French (2012) argues against Turri (2010) arguments against the Entailment Thesis. But French appeals to broadly linguistic considerations, while in this paper I am appealing to broadly epistemological considerations. In fact, it would be interesting to see how one's theory of the nature of propositional perception informed how one ought to respond to the three general arguments I discuss in this paper. For example, Craig French point out that if we think of the nature of propositional perception as a propositional-perceptual state, where there need be no necessary epistemic conditions on its obtaining, then the worry with the Straightforward Response from Sect. 2 seems to be a good one. On the other hand, if we think of the nature of propositional perception as a epistemic-perceptual state - that is, as having epistemic conditions, such as putting the perceiver in a position to know that $p$ for its obtaining - then the Straightforward Response looks more plausible for the proponent of this view of the nature of propositional perception.
} 
just that it might look hard to reconcile the fact that Smith saw a barn in close range, applied the concept $<$ barn $>$ to the barn, the barn looked to him to be a barn, with the alleged fact that Smith nevertheless failed to see that it was a barn. On the other hand, if one thinks that seeing that $\mathrm{p}$ is an epistemic state which amounts to knowing that $\mathrm{p}$, then one is free to think that, since one of the epistemic conditions of seeing that $\mathrm{p}$ is not satisfied-knowing that $p$ - it follows that Smith didn't see that $\mathrm{p}$ either. The thought here is that the considerations I adduced above won't count against the Straightforward Response, because the distinctively epistemic conditions on seeing that $\mathrm{p}$ weren't met.

But the proponent of the Entailment Thesis could mount a different objection. I will return to this point in a moment, where I present an argument for the Positive Response. But for now, let us turn to the second option: the Negative Response. The Negative Response looks plausible as well. After all, BARN at least looks like a Gettier case. And if it is a Gettier case, Smith doesn't know that a barn is there. But this is compatible, so the thought goes, with him still seeing that a barn is there. Indeed, as Pritchard has pointed out, wouldn't it make sense for Smith, in retrospect, to claim that while he saw that a barn was there, he just didn't know that it was a barn? ${ }^{9}$ If this is right, then it looks as if one can see that $\mathrm{p}$, but not know that $\mathrm{p}$, because seeing that p does not guarantee that we have fulfilled the anti-luck condition on knowledge. Call this the Argument from Luck.

I want to pause here to examine this argument in more detail. First, we need to make more clear what epistemic luck is supposed to be. What we want to understand is how luck prevents the agent who sees that a barn is there from knowing that a barn is there. It is no longer the case that epistemologists have no clear and developed conception of epistemic luck. Instead, there are at least two accounts of the epistemic luck condition on propositional knowledge, expressed as modal conditions on belief. What we should examine in more detail, then, is whether Smith fails to meet these conditions. If he doesn't, then we will have good reason for thinking that the Argument from Luck stands.

How do we articulate the anti-luck condition on knowledge? Several epistemologists have framed the anti-luck condition in terms of certain modal conditions. The two most prominent modal conditions are the sensitivity condition (Nozick 1981; Dretske 1971) and the safety condition (Sosa 1999; Williamson 2000; Pritchard 2005, 2009). According to the sensitivity condition:

(SENSITIVITY) S's belief that $\mathrm{p}$ is sensitive iff in all nearby possible worlds in which $\sim \mathrm{p}, \mathrm{S}$ does not believe that $\mathrm{p} .^{10}$

\footnotetext{
9 Pritchard (2011,pp. 442-443) and McDowell (2002,p. 277) makes this point [indeed, the case McDowell gives is structurally analogous to Turri (2010, p. 199) "Rabbit" case] where the agent in McDowell's case believed that the object merely appeared green because he justifiedly thought it was under a color distorting light, even though he later discovers there was no such light, and he actually saw that it was green.

10 Nozick's expression of this condition was in terms of the subjunctive conditional: $\sim \mathrm{p} \square \rightarrow \sim \mathrm{B}(\mathrm{p})$. That is, if $\mathrm{p}$ were false, I wouldn't believe that $\mathrm{p}$. He later refines the principle in his (1981, Chap. 3, §III), relativizing it to an epistemic basis. On this model, where $b$ is a basis for belief, the condition would read: $\sim \mathrm{p} \square \rightarrow \sim \mathrm{B}(\mathrm{p})$ on basis $b$.
} 
For example, to borrow a famous example from Nozick, if I were a brain in a vat, I wouldn't believe that I was. That is, if 'I am not a brain in a vat' were false, I would nevertheless continue to believe that 'I am not a brain in a vat' were true. And this makes the belief that 'I am not a brain in a vat' not a sensitive belief, even if it is true that I'm not a brain in a vat.

Now, it seems like in all nearby possible worlds in which it is not the case that a barn is in front of Smith, he still believes that there is. After all, those fake barns look just like real barns. The proponent of the Argument from Luck can therefore appeal to the sensitivity condition in order to explain Smith's lack of knowledge.

Of course, this is just one popular articulation of the anti-luck condition on knowledge. But in order to avoid some of the complications with this principle, some epistemologists have adopted a similar, though quite distinct, modal condition on knowledge: 11

(SAFETY) S's belief that $\mathrm{p}$ is safe iff in all nearby possible worlds in which $\mathrm{S}$ believes that $\mathrm{p}, \mathrm{p}$ is true. ${ }^{12}$

For example, I believe right now that a computer is in front of me because of what I see. And if I continued to believe that a computer is in front of me on the basis of what I see to be so, my belief that it is in front of me would continue to be true. In general, if our belief forming mechanisms, or the epistemic bases from which we believe a target proposition $\mathrm{p}$ are good enough to make sure that we would continue to have a true belief in counterfactual situations, or in nearby possible worlds, then the belief is safe.

Now, it at least seems like Smith's belief is unsafe. In all those nearby possible worlds in which he believes that a barn is in front of him, he would be wrong. After all, too easily could he have come upon a fake barn which looks just like a barn.

The proponent of the Argument from Luck therefore has a powerful case. She can argue that Smith's belief that a barn is in front of him is neither safe nor sensitive. But if either of those principles properly articulates the anti-luck condition on knowledge, then Smith's belief fails to count as knowledge.

How should the proponent of the Entailment Thesis respond to this argument? I will argue that she should claim - contra initial appearances-that Smith meets both of those anti-luck conditions on knowledge. I will pursue this argument as follows.

\footnotetext{
11 The complications with sensitivity are not relevant for our purposes, so I'll only briefly register them here. The complications include the possibility of inductive knowledge, Sosa (1999) 'Garbage Chute' case, and the denial of the Closure Principle on knowledge (roughly, the principle that if $\mathrm{S}$ knows that $p$, and $\mathrm{S}$ knows that $(p \vdash q)$, then $\mathrm{S}$ knows that $q))$. Also, note that I am avoiding interesting issues about whether or not either of sensitivity or safety, however formulated, really does articulate the anti-luck condition on knowledge. There are arguments on offer for the claim that, while propositional knowledge excludes epistemic luck, neither of safety nor sensitivity in any of their formulations properly expresses the anti-luck condition. See Hiller and Neta (2007), Vogel (2007), and Lackey (2008).

12 I want to register that there are at least three different expressions of the safety condition on offer. Here's Williamson's (2000, p. 147) version: "if one knows, one could not easily have been wrong in a similar case". Pritchard (2007, p. 281): "S's belief is safe iff in most near-by possible worlds in which S continues to form her belief about the target proposition in the same way as in the actual world the belief continues to be true". And Sosa (1999, p. 146): "If S were to believe that p, p would be true", though Sosa relativizes safety to a basis later in his (2007).
} 
First, we need to distinguish between getting things right-e.g., forming a true belief rather than a false belief-as a matter of luck because of our circumstances, and getting things right as a matter of luck because of the basis from which we believe the target proposition. ${ }^{13}$ Second, I will show how Smith's getting a true belief rather than a false belief is a matter of luck in the first sense but not the second sense. But the second sense is what matters for epistemic assessment and appraisal. The conclusion is that the Argument from Luck is not sound-Smith meets various antiluck conditions on knowledge. If one retains the intuition that Smith nevertheless does not know that a barn is in front of him, something else must be explaining that intuition if it is indeed accurate. If not, the intuition has otherwise been rendered harmless.

\subsection{Resisting the argument from luck}

The proponent of the Argument from Luck maintains that Smith sees that a barn is there, but does not know that a barn is there because he got things right rather than wrong because of some knowledge-excluding imposition of luck. It is then argued that because knowledge excludes luck, Smith does not know that a barn is there, even though he sees that it is there, which is incompatible with the Entailment Thesis.

But the proponent of the Entailment Thesis should question the second step. Did Smith get things right rather than wrong because of some imposition of luck? And if he did, was this imposition of luck the kind of luck that prevents him from knowing that a barn is there?

It should be granted that it is a matter of luck that what Smith came upon was a barn and not a fake-barn. And his coming upon a barn of course enabled him to see what he saw: a barn. But that his belief is true rather than false, given his epistemic basis which supports his belief, is not a matter of luck. Were he to believe that a barn is there on the basis of seeing that it is there, his belief would be true. Likewise, were it false that a barn was in front of him, it would also be false that he would believe the same proposition on the same basis.

Consider Sosa's account of the safety condition. Sosa relativizes safety to a basis, where a "belief cannot constitute knowledge if the believer might too easily have so believed on the same basis while his belief was false" (Sosa 2008, p. 124). Now, Smith meets this safety condition. His perceptual basis is propositional perception. Indeed, both the proponent of the Entailment Thesis and the proponent of the Argument from Luck agree on this point. Both can agree that the agent sees that a barn is there and not just sees a barn. But then it follows that, from Smith's perceptual basis-propositional perception - not very easily would it have been false if based on that basis. In other words, given Smith's basis, not very easily would his belief have been false because not possibly could his belief have been false-again, given his basis. Consider, then, this revised version of the safety principle:

13 This distinction can be found in Pritchard (2005), and first in Engel (1992) as the distinction between evidential luck and veritic luck. See also Unger (1968) for three other distinctions between types of luck, none of which, he argues, are incompatible with knowledge. 
(SAFE BASIS) S's belief that $\mathrm{p}$ is basis relative safe iff in all nearby possible worlds in which $\mathrm{S}$ believes that $\mathrm{p}$ on basis $B$, S's belief that $\mathrm{p}$ is true.

Smith meets this condition as follows:

(SAFE BASIS BARN) In all nearby possible worlds in which Smith believes that a barn is there on the basis of propositional perception-for example, on the basis of seeing that a barn is there-his belief is true.

And Smith also meets the basis-relative version of sensitivity as follows ${ }^{14}$ :

(SENSITIVE BASIS BARN) In all nearby possible worlds in which it is false that a barn is there, in front of Smith, he does not continue to believe that it is there on the basis of propositional perception-for example, on the basis of seeing that it is there.

When we index the agent's epistemic basis, the crucial premise of the Argument from Luck becomes neutralized. It should not be maintained that what the agent sees is that a barn is there, while he nevertheless does not know that a barn is there because of some imposition of knowledge-excluding luck. As I argued here, the kind of luck that does afflict the agent in BARN is not the kind that prevents him from knowing that a barn is there. The agent only luckily came upon a barn rather than a fake barn. This only luckily put him in a position to have the evidence that he has. But given the evidence he got through the good grace of good luck, his belief is true, and it would continue to be true insofar as he continued to believe the same proposition on that basis. $^{15}$

I want to close this section with some important points. The first point is this: perhaps the sensitive and safe basis conditions are not the luck-excluding conditions required for knowledge. But if that is right, then so much the worse for the proponents of the Argument from Luck. The thought here is that the proponents of this argument have some conception of luck that they're appealing to in assessing whether or not the agent knows in BARN, and it is this conception which propositional perception can fail to exclude. But what conception is that? If it is not the conception embodied in either of the safety or sensitivity conditions on knowledge and their analogues, then it is not clear which conception they had in mind, if any at all. The second point is that it's unclear whether or not what I have argued here is incompatible with the verdict in Goldman (1976) barn-case. First, notice that in Goldman's case, he was not specific about the agent's epistemic belief forming basis for the target proposition-at least, not as specific as the proponents of the Argument from Luck are with their barn case. I have argued that if the agent's belief forming basis is propositional perception, then given that propositional perception satisfies various anti-luck conditions, it follows that the agent knows that a barn is there. The proponent of the Argument from Luck

\footnotetext{
14 Nozick relativizes sensitivity to an evidential basis in his (1981 p. 179)

15 Perhaps one will agree with me that in BARN, S satisfies the anti-luck conditions on knowledge, but nevertheless maintain that $\mathrm{S}$ still fails to know that a barn is in front of them for other reasons independently of the anti-luck conditions. At this juncture, the proponent of the Entailment Thesis could then mount the Straightforward Response. After all, this is compatible with the argument against the Argument from Luck that I provided being successful. Thanks to an anonymous reviewer for this helpful suggestion.
} 
accepts the antecedent, and I have urged here that proponents of the Entailment Thesis should as well. But one can grant this without also conceding that Goldman's verdict in the original barn case was wrong. The two verdicts are compatible. But how?

We should return to the distinction between good luck placing us in a position to have the epistemic basis that we have for a target proposition and good luck making our belief true rather than false, irrespective of our epistemic basis for that belief. For example, if I flip through pages in a book, and just guess that I will land on page 323, then even if I formed a true belief, guesswork is not the kind of epistemic support, or evidential basis, or in general epistemic basis, which would have allowed me to continue to a have true belief rather than a false belief in different circumstances. In these circumstances, guessing got me a true belief rather than a false belief, but had things been different, guessing could have given me a false belief. But this is not true of some epistemic bases. Propositional perception is such that whenever I believe that $\mathrm{p}$ on the basis of perceiving that $\mathrm{p}$, the belief will be true. In this fashion, propositional perception is not susceptible to what Engel (1992) called veritic luck:

(VERITIC LUCK) An agent S's belief that $\mathrm{p}$ in circumstance $\mathrm{C}$ is veritically lucky iff given S's evidence for $\mathrm{p}$, it is just a matter of luck that S's belief that $\mathrm{p}$ is true in $\mathrm{C}$.

Veritic luck is the kind of luck that looks incompatible with knowledge. And notice that Smith's belief that a barn is there is not vertically lucky. For given that his basis in BARN is propositional perception, it is not just a matter of luck that his belief that a barn is there is true rather than false in those circumstances. But now here is the crucial point for the proponents of Goldman's verdict in his original barn case. Barn cases can be set up so that the agent does not have propositional perception as their epistemic basis. We can imagine that Smith's epistemic basis is instead a visual experience or impression as of a barn being there. In this case, if Smith's epistemic basis for believing that a barn is there is his having a visual experience as of barn being there, this basis does not eliminate knowledge-excluding luck. In all nearby worlds in which Smith has an experience as of a barn being there, a barn isn't there. After all, there's plenty of nearby worlds where Smith has the same epistemic basis as he does in the actual world, since sufficient for having an experience as of a barn being there is simply seeing a fake-barn. So, if we index Smith's epistemic basis to a visual experience as of a barn being there, he won't satisfy SAFE BASIS, since too easily could his basis have given him a false belief. So too with SENSITIVE BASIS, since had a fake-barn been in front of him, he still would have believed that it was a barn on the basis of having an experience as of a barn being there. In general, then, if the agent's epistemic basis is construed to be something like having a visual experience as of a barn being there, then even if in the actual world he is standing in front of the barn, and believes that a barn is there on the basis of having an experience as of a barn being there, this belief will be true, but vertically luckily true, and so not knowledge.

So, perhaps what makes the difference in whether we should assess the agent in a barn case as knowing or not knowing is their epistemic basis in those cases. If the basis is propositional perception, as the proponent of the Argument from Luck maintains, we have good reason for rejecting the claim that the agent does not know that a barn is 
there. But, again, this is compatible with different verdicts in other barn cases where the epistemic basis has changed.

But now, what if someone maintains that Smith fulfills those anti-luck conditions on knowledge, but nevertheless does not fulfill all of the relevant anti-luck conditions on knowledge? How should the proponent of the Entailment Thesis respond?

Of course, it is open to the proponent of the Entailment Thesis to fall back on the Straightforward Response, if that position can be sustained. But one can also inquire into the nature of the kind of luck that is, according to this opponent, knowledgeexcluding in BARN. At this juncture, the kind of luck that might be knowledgeexcluding is some kind of environmental-luck, if the argument I have given against the Argument from Luck is sound. On this view, Smith's coming upon the one barn and seeing that it is there rather than a fake barn is lucky in a way that is knowledgeexcluding, despite the fulfillment of the other anti-luck conditions on knowledge that I distinguished. Two kinds of environmental-luck are relevant to our discussion here:

(1) The luckiness of 'there is a barn here' being true, in the circumstances in which there are more fake-barns around.

(2) The luckiness of ' $\mathrm{S}$ came upon and saw that a barn was there' being true, in the circumstances in which there are more fake-barns around.

A proposition can be known even if it is a contingent truth. If one maintains that Smith does not know that a barn is there because of the kind of luck present in (1), it is hard to see how we avoid the implausible consequence that no one can know contingent truths. What explains the luckiness of (2), on the other hand, is that there is some sense in which Smith could very easily have come upon one of the fake-barns, given their prevalance in the area. If Smith had done so, he might have formed the false demonstrative belief that that (the barn in front of him) is a barn, or the true general belief that $a$ barn is in the field. But I argued that once we index the anti-luck conditions to the relevant epistemic basis—propositional perception-it's not a matter of luck that the agent formed a true rather than a false belief. Otherwise, it offends against the orthodox on the nature of epistemic luck that the kind of luck present in (2) is knowledge-excluding, unless one's epistemic basis fails to have a non-accidental connection to the facts, which I argued earlier is not the case. ${ }^{16}$

A final point on this score is that the argument I've presented here against the Argument from Luck is not an argument for the truth of the Entailment Thesis, nor is it an argument for the view that agents can know that a barn is in front of them in barn-cases. The conclusion of the argument is supposed to be modest. It's just that the proponent of the Entailment Thesis can grant the premise of the Argument from Luck that the agent sees that a barn is in front of them and consistently maintain that the agent thereby knows that a barn is there without offending against the core anti-luck intuitions.

$\overline{16}$ Cf. Unger (1968), Engel (1992), and Pritchard (2004, 2005, 2013). For discussion, see Engel (2011). 


\section{The argument from defeat}

One might be tempted at this juncture to maintain that what can go wrong for the agent in BARN is that there is a known defeater present which prevents the agent from knowing that a barn is there. For example, that fake-barns are present defeats, not his seeing that a barn is there, but his knowing that a barn is there. Consider the following reasoning adapted from Pritchard (2011, pp. 442-443) in support of this view:

(D1) Smith sees that a barn is there.

(D2) Smith ought not believe that a barn is there. His reliable friend Jones told him that fake barns are abound, and that these fake barns look just like barns.

From (D1), it follows that:

(D3) If the Entailment Thesis is true, Smith knows that a barn is there.

Now suppose that the Entailment Thesis is true. From (D1) and (D3) it follows that:

(C1) Smith knows that a barn is there.

But from (C1) and (D2) it follows that:

(C2) Smith ought not believe that a barn is there and Smith knows that a barn is there.

(C2) is taken to be a contradiction. If Smith knows that $\mathrm{p}$, then it is not the case that he ought not believe that p. So (D1) - (C2) is taken to be a reductio of the Entailment Thesis. Call this the Argument from Defeat.

The Argument from Defeat appears to be valid. But is it sound? Consider the following support for (D1) and (D2) from Pritchard (2011):

Suppose, for example, that one is in a situation in which one is genuinely visually presented with a barn and circumstances are in fact epistemically good (there's no deception in play, one's faculties are functioning correctly, and so on). But now suppose further that one has been told, by an otherwise reliable informant, that one is presently being deceived (that one is in barn facade county, say), even though this is in fact not the case. Clearly, in such a case one ought not to believe the target proposition, and hence one cannot possibly know this proposition either. (Indeed, if one did continue to believe the target proposition even despite the presence of this undefeated defeater, then one would still lack knowledge). Still, does it follow that one does not see that the target proposition obtains? I think not. [...] For suppose that one were to discover subsequently that the testimony one received was false, but that everything else one knows about the circumstances in which one was presented with this (apparent) barn remained the same. Wouldn't one now retrospectively treat oneself as having earlier seen that there was a barn? Think, for example, about how one would describe one's situation in this regard were one to be asked about it. Wouldn't it be most natural to say that one did see that there was a barn in the field, rather than to 'hedge' one's assertion by saying, for example, that one merely thought that one saw a barn? (Pritchard 2011, pp. 442-443). 
Of course, notice that in order for (C2) to be a genuine contradiction, it has to also be true that if $\mathrm{S}$ knows that $\mathrm{p}, \mathrm{S}$ ought to believe that $\mathrm{p}$. Contraposed, if it is not the case that $S$ ought to believe that $p$, then it is not the case that $S$ knows that $p$. This principle is exploited in Pritchard's reasoning in the third sentence: "Clearly, in such a case one ought not to believe the target proposition, and hence one cannot possibly know this proposition either" (Pritchard 2011, pp. 442-443). With this in mind, we are now in a position to make more explicit Pritchard's reasoning and the principles that reasoning relies on:

(PROPOSITIONAL PERCEPTION) S sees that a barn is there.

(DEFEATER CONDITION) If a reliable informant tells $\mathrm{S}$ that fake barns are abound, then $\mathrm{S}$ ought not believe that a barn is there. ${ }^{17}$

(DEFEATER) A reliable informant tells $S$ that fake barns are abound.

(ENTAILMENT THESIS) If $\mathrm{S}$ sees that a barn is there, $\mathrm{S}$ knows that a barn is there.

(EPISTEMIC OUGHT) If it is not the case that $\mathrm{S}$ ought to believe that a barn is there, then it is not the case that $\mathrm{S}$ knows that a barn is there. ${ }^{18}$

From (PROPOSITIONAL PERCEPTION) and (ENTAILMENT THESIS), it follows that $\mathrm{S}$ knows that a barn is there. But from (DEFEATER CONDITION) and (DEFEATER) it follows that $S$ ought not believe that a barn is there. However, from (EPISTEMIC OUGHT) it now follows that $\mathrm{S}$ does not know that a barn is there - contradiction. In order to resolve the contradiction, Pritchard eliminates (ENTAILMENT THESIS). But I think that this is the wrong move. Instead, we should focus on (PROPOSITIONAL PERCEPTION), (DEFEATER), (DEFEATER CONDITION), and (EPISTEMIC OUGHT).

Consider first (DEFEATER). One might want to argue that if Jones is reliable and Jones tells Smith that fake barns are abound, then Smith ought not believe that a barn is there, in front of him. This looks plausible. But the proponent of the Entailment Thesis can be dogmatic, and insist that Smith's seeing that a barn is there defeats that defeater. We can imagine Smith telling Jones the following: "Perhaps there are fake barns around, but I can just see that this is a barn." Of course, the response to this jumps off the page. Jones might respond that Smith still ought not believe that a barn is there, even if it is true that he sees that a barn is there. This response maintains that rejecting (DEFEATER) is too dogmatic.

\footnotetext{
17 This premise is drawn out from the following quotation from Pritchard (2011): "But now suppose further that one has been told, by an otherwise reliable informant, that one is presently being deceived (that one is in barn facade county, say), even though this is in fact not the case. Clearly, in such a case one ought not to believe the target proposition [...]" (ibid.).

18 I draw out (EPISTEMIC OUGHT) from the remaining quotation in footnote 12 of Pritchard (2011): “[...] and hence one cannot possibly know this proposition either. (Indeed, if one did continue to believe the target proposition even despite the presence of this undefeated defeater, then one would still lack knowledge)." In any case, the Argument from Defeat would be fallacious without this principle in play.
} 
Moreover, notice that one could also mount a response to the Argument from Defeat which mirrors the 'Straightforward Response' from BARN. According to this response, if S doesn't know that a barn is there, because she ought not believe that it is there, then so too she doesn't see that it is there. The core thought here is that seeing that $\mathrm{p}$ is an epistemic state - a state where the satisfaction of ' $\mathrm{S}$ sees that $\mathrm{p}$ ' includes the satisfaction of certain epistemological conditions, the core condition being knowing that $p$. On this score, what is relevant to whether or not $\mathrm{S}$ knows in these circumstances will also be relevant to whether or not $\mathrm{S}$ sees that such-and-such is so in these circumstances. If S isn't in a position to know that a barn is there, because she ought not believe that one is here, then she's also not in a position to see that it is there either.

Against this, the proponent of Pritchard's reasoning would need to give us further considerations in favor of the idea that $S$ really does see that the barn is there, perhaps considerations that fall out of one's view of propositional perception. Instead, Pritchard's considerations appeal to the idea that it is simply less natural to hedge our claim from 'I saw that a barn was there' to 'I seemed to see that a barn was there', and that this is what provides support for S's having seen that a barn is there. The debate at this juncture, however, should turn on how we should understand propositional perception, and not only on our intuitions about ascriptions of propositional perceptual states.

So let us now consider (DEFEATER CONDITION). This condition is problematic as well, but not because it is false. It is problematic because if we grant that Smith sees that a barn is there, and so he believes that it is there, how can he both see that a barn is there and withhold belief that it is there? Consider the following intuitive principles:

(+EPISTEMIC OUGHT IMPLIES CAN) If $\mathrm{S}$ ought to believe that $\mathrm{p}, \mathrm{S}$ can believe that $\mathrm{p}$.

\section{(-EPISTEMIC OUGHT IMPLIES CAN) If $S$ ought to withhold belief that $p$,}

S can withhold belief that p. ${ }^{19}$

The Argument from Defeat implies that Smith sees that a barn is there and that he ought not believe that a barn is there. But if Smith ought not believe that a barn is there, it must also be true that he can withhold believing that a barn is there. Of course, this is no obstacle in its own right. One can withhold believing that a barn is there and it can be true that one ought not believe that a barn is there. This, in itself, poses no threat. But it poses a threat when we conjoin it with the fact that Smith sees that a barn

\footnotetext{
19 Let's make clear a certain ambiguity in this principle. Let $\mathrm{O}$ be a deontic operator for 'ought', and B be the belief predicate. From $\mathrm{O}(\mathrm{S}, \sim \mathrm{B}[\mathrm{p}])$ it does not follow that $\mathrm{O}(\mathrm{S}, \mathrm{B}[\sim \mathrm{p}])$, nor does it follow from $\sim \mathrm{O}(\mathrm{S}, \mathrm{B}[\mathrm{p}])$ that $\mathrm{O}(\mathrm{S}, \sim \mathrm{B}[\mathrm{p}])$. In $\sim \mathrm{O}(\mathrm{S}, \mathrm{B}[\mathrm{p}])$, the negation operator is ranging over the ought operator, whereas in $\mathrm{O}(\mathrm{S}, \sim \mathrm{B}[\mathrm{p}])$ the negation operator is ranging over the belief predicate. In the first case, what ought not be the case is $\mathrm{S}$ believing that $\mathrm{p}$. In the second case, what ought to be the case is $\mathrm{S}$ not believing that $\mathrm{p}$. The (-EPISTEMIC OUGHT IMPLIES CAN) principles' antecedent says that what ought to be the case is $\mathrm{S}$ withholding belief that $\mathrm{p}$, that is, not believing that $\mathrm{p}$. So, the (-EPISTEMIC OUGHT IMPLIES $\mathrm{CAN})$ principle says that $\mathrm{O}(\mathrm{S}, \sim \mathrm{B}[\mathrm{p}]) \rightarrow \diamond \sim \mathrm{B}(\mathrm{S}, \mathrm{p})$. The intuitiveness of this principle, I take it, derives from the analogous ethical principle that, if what ought to be the case is $\mathrm{S}$ not $\phi i n g$, then it has to at least be logically possible for S not to $\phi$. After all, if one's ethical principle entailed that everyone ought to successfully divide by zero, even though no one could ever successfully divide by zero, that would just be a bad ethical principle: it would entail that we should do what we cannot do. Here, I am just taking it that the same is true for normative epistemological principles.
} 
is there. The proponent of the Argument from Defeat relies on the premise that Smith sees that a barn is there. But how can the proponent of the Argument from Defeat consistently maintain that $\mathrm{S}$ sees that a barn is there, and that $\mathrm{S}$ ought to withhold belief that a barn is there? From (-EPISTEMIC OUGHT IMPLIES CAN), it follows that $S$ can withhold belief that a barn is there. But that looks incompatible with seeing that a barn is there, since seeing that $\mathrm{p}$ seems to require believing that $\mathrm{p}$. So, if the Argument from Defeat is sound, then the following principle is false:

(PROPOSITIONAL PERCEPTION ENTAILS BELIEF) If $S$ sees that $p, S$ believes that $\mathrm{p}$.

But this principle seems to be true. How can we make sense of the fact that $\mathrm{S}$ sees that a barn is there rather than just seeing a barn, if it is not also the case that $S$ believes that what he sees is a barn? Indeed, the most sustained theories of propositional perception (Dretske 1969; Cassam 2007a,b; Stroud 2002, 2011) take it that what distinguishes objectual perception from propositional perception-seeing an object o which is $\mathrm{F}$ versus seeing that $\mathrm{o}$ is $\mathrm{F}$-is that the latter, but not the former, requires acquiring the belief that $\mathrm{o}$ is $\mathrm{F}$ as a result of seeing an o which is $\mathrm{F}$. The claim here, then, is that the Argument from Defeat is not conclusive, because it requires that $\mathrm{S}$ can see that $\mathrm{p}$ and not believe that $\mathrm{p}$. But that is still an un-argued assumption. For all the proponent of the Entailment Thesis is concerned, we have good reasons for thinking that one cannot see that $\mathrm{p}$ unless we believe that $\mathrm{p}$. The proponent of the Argument from Defeat will therefore have to mount an objection which shows that it is possible to both see that $p$ and nevertheless not believe that p. Unless that claim can be sustained, the Argument from Defeat will be ineffective.

\section{The argument from belief}

The final argument against the Entailment Thesis that we will be considering is what I call the Argument from Belief. This argument moves from the premise that propositional knowledge entails belief, and the premise that one can see that p even if one does not believe that $\mathrm{p}$, to the conclusion that one can see that $\mathrm{p}$ even if one does not know that $\mathrm{p}$. The crucial premise is the second premise: $\mathrm{S}$ can see that $\mathrm{p}$ even if $\mathrm{S}$ does not believe that p. In his (2010), John Turri provides two cases which aim to support this premise. The first case involves an agent who looks at what appears to be Müller-Lyer lines. Confidently, the agent asserts that the two lines are unequal in length. But in fact the lines aren't Müeller-Lyer lines, and instead really are as they visually appear to be: equal in length. So, Turri argues that while the agent saw that the lines were equal in length, he just didn't believe that they were. Turri calls this case (LINES). In the second case, the agent thinks that he is involved in an experiment with hallucinogenic drugs. Later, a mechanical rabbit appears to enter the room. Yet, our agent doesn't believe that he sees a mechanical rabbit, because he is under the impression that he is hallucinating. However, he later discovers that a mechanical rabbit did enter the room, and so he saw that it was a mechanical rabbit. Turri calls this case (RABBIT). ${ }^{20}$

$\overline{20}$ For the full examples, see Turri (2010, pp. 198-199). 
Each of these examples follow the same pattern. The first step can be expressed as follows:

(STEP 1) A misleading defeater is introduced.

For example, in Pritchard's case it is the reliable testifier who tells $S$ that all kinds of fake barns are around, even though there aren't. In Turri's (LINES) case, it is what $S$ believes to be a visual illusion but isn't, and in his (RABBIT) case, it is what $\mathrm{S}$ believes to be a hallucination, but isn't. The second step is:

(STEP 2) S characterizes herself as having seen that $\mathrm{p}$.

In Pritchard's case, he relies on the idea that it makes sense, in retrospect, to treat $S$ as having seen that a barn was in front of him, and that it also makes sense for $\mathrm{S}$ to not hedge her claim of having seen that a barn was there. In the (LINES) case, Turri relies on the idea that it makes sense, in retrospect, to treat $\mathrm{S}$ as having seen that the bottom line is the same length as the top line. Likewise, in the (RABBIT) case, Turri relies on the idea that it makes sense to treat $S$ as having seen that the mechanical rabbit was in front of him. Note that the reason it seems to make sense to treat all of these agents as having seen that $\mathrm{p}$ is that there seems to be nothing built into these cases that makes it look like that agent could not have seen the relevant objects and properties and so could not have seen that certain propositions are true of those objects and properties. But then we also get:

(STEP 3) S characterizes herself as not having believed that $\mathrm{p}$.

STEP 1 makes STEP 3 look plausible. Each agent believes that something abnormal is taking place, e.g., one believes that lots of fake barns which look like barns are around, one believes that they are undergoing a visual illusion, and one believes that they are hallucinating. But if $\mathrm{S}$ believes that lots of fake barns indistinguishable from barns are around, how can $\mathrm{S}$ also believe that what she sees is now a barn? Likewise, if $\mathrm{S}$ believes that she is undergoing a visual illusion, how can she also believe that the bottom line and the top line are the same length? And so on. Of course, notice that none of this implies that the agents could not believe that what seems to be the case is the case. But if it is intelligible for each agent to treat themselves, in retrospect, as having seen that $\mathrm{p}$ even though at the time none of the agents believed that $\mathrm{p}$, this is supposed to be a counter-example to the thesis that if $\mathrm{S}$ saw that $\mathrm{p}, \mathrm{S}$ believed that $\mathrm{p}$.

\subsection{Neutralizing the argument from belief}

How persuasive is the Argument from Belief? As with the Argument from Luck and the Argument from Defeat, it is open to the defender of the Entailment Thesis to maintain a Straightforward Response. In this case, one can concede that because we do not believe that p, we don't know that p. But then if the Entailment Thesis is true, it follows that we did not see that $\mathrm{p}$ either. So we have no counter-example to the Entailment Thesis unless one provides good reasons for thinking that we do believe that $\mathrm{p}$ and that knowledge entails belief.

Are there other responses available to the proponent of the Entailment Thesis? We might think that the Argument from Belief puts just as much pressure on its premises 
as it does on the proponent of the Entailment Thesis. For example, the proponent of the Entailment Thesis can grant the proponent of the Argument from Belief the central premise that:

(Belief Premise) S sees that $\mathrm{p}$ and does not believe that $\mathrm{p}$.

But take issue with whether or not this alone is sufficient to generate a good argument against the Entailment Thesis. The proponent of the Argument from Belief, recall, argues that:

(Knowledge Entails Belief) If $\mathrm{S}$ knows that $\mathrm{p}, \mathrm{S}$ believes that $\mathrm{p}$.

(Belief Premise) $\mathrm{S}$ sees that $\mathrm{p}$ and does not believe that $\mathrm{p}$.

$\therefore$ (Belief Conclusion) $\mathrm{S}$ sees that $\mathrm{p}$ and does not know that $\mathrm{p}$.

But this argument relies on the so far un-argued assumption that knowledge entails belief. Perhaps this view is non-negotiable. But the assumption that propositional seeing or perceiving entails knowing can take on the same status. This too might be an intuition that we are unwilling to concede. ${ }^{21}$ The point here, then, is just that we can make sense of the idea that the Entailment Thesis is non-negotiable. If that is right, then the central premise of the Argument from Belief can be used to argue in the reverse direction as follows:

(Entailment Thesis) If $\mathrm{S}$ sees that $\mathrm{p}, \mathrm{S}$ knows that $\mathrm{p}$.

(Belief Premise) $\mathrm{S}$ sees that $\mathrm{p}$ and does not believe that $\mathrm{p}$.

$\therefore(\sim$ Knowledge Entails Belief) $\mathrm{S}$ knows that $\mathrm{p}$ and does not believe that $\mathrm{p}$.

In other words, the premise that the proponent of the Argument from Belief uses to support the conclusion that the Entailment Thesis is false is the same premise that the proponent of the Entailment Thesis can use to support the conclusion that the Knowledge Entails Belief Thesis is false. ${ }^{22}$ The idea that I want to reinforce here is that the Argument from Belief as it stands gives us at least as much grounds

\footnotetext{
21 Why might one think the Entailment Thesis is non-negotiable? Well, one could maintain that it is part of the concept of propositional perception that it has certain necessary epistemological conditions, such as knowing that p. Cf. Cassam (2008, p. 38), where he discusses this idea. Note that their discussion does not bear directly on the present concern in the text, but one does find expression of the idea that propositional knowledge is a necessary condition of propositional perception. The core thought in the text, however, is that, insofar as we think we can and often do see that such and such is so in the world around us, then because knowing that such and such is so is a necessary condition of that kind of perceptual state, the Entailment Thesis is, in consequence, non-negotiable. A similar thought for the Knowledge Entails Belief principle might run like this: it is because we can and often do know that such and such is so, and because it is a necessary condition of this state being instantiated that we believe that such and such is so, that the Knowledge Entails Belief principle is non-negotiable. What I am doing in the main body of the text is just highlighting how the reasoning on this score might run along the same lines, and so simply appealing to either of these principles alone, plus the relevant premise in the Argument from Belief, will be no more effective than, or at least as effective as, the other principle. The thought here is that both moves are available because one can, at least on the surface, consistently maintain that either principle is non-negotiable, so a simple appeal to one principle over the other will remain an ineffective dialectical move, as made more explicit in Sect. 4.1.

22 To be sure, most epistemologists do take the Knowledge Entails Belief principle to be non-negotiable. But there is also a long epistemological tradition which questions this principle. See Plato's Republic, pp. 476-479, Prichard (1950), Woozley (1953), and Radford (1966).
} 
for thinking that knowledge does not entail belief as it does for thinking that we can see that something is so but not know that it is so. A successful argument from belief against the Entailment Thesis will explain what makes this move unavailable. Otherwise, the Argument from Belief is just an appeal to intuitions. But we wanted the argument to decide the fate of the Entailment Thesis rather than leave us with a stalemate.

The second problem is that the example proves too much. It is less clear that the example shows that it is possible to see that $\mathrm{p}$ and not believe that $\mathrm{p}$, rather than just showing that sentences of the following form are intelligible ' $S$ saw that $p$, but $S$ did not believe that p'. But that the sentence is intelligible need not be indefeasible evidence that it is not a contradiction. After all, the sentence (A) 'John found the mask under his desk, but it wasn't there' is intelligible, but false and false because it is a contradiction, just as (B) 'Jones remembered the car crash, but the police knew that it was not a crash' is intelligible and false, and false because it is a contradiction. So too, we can imagine that ' $\mathrm{S}$ saw that the lines were the same length, he just failed to believe it' is intelligible and false, and false because it is a contradiction. This might indeed not be true, but the example does not show that it is not true, just as the intelligibility of sentences (A) and (B) doesn't settle the matter over their contradictoriness or non-contradictoriness. To be clear, this argument is not intended to show that the case in favor of the second premise of the Argument from Belief is a not a counter-example to the thesis that $S$ can see that $p$ and not believe that $\mathrm{p}$, but is instead intended to be an argument against its conclusiveness. What I am urging here is that there is gap between showing that a certain sentence or utterance is intelligible and showing that a certain sentence or utterance is not a contradiction. There are cases of sentences or utterances which are both intelligible and contradictions. So their intelligibility cannot be indefeasible evidence of their non-contradictoriness. What else is needed is some explanation which closes this gap; some explanation which tells us that what explains its intelligibility is its noncontradictoriness. And we might think that one way to close this gap is to provide an analysis of both ' $S$ sees that $p$ ' and ' $S$ believes that $p$ ' which reveals that the content of the latter is not contained in or otherwise presupposed by the content of the former.

But we should not let the Entailment Thesis hang on the success of these arguments alone. There are other, perhaps more fundamental worries that we might have with the Argument from Belief. One such problem is that the case does not respect the distinction between occurrent belief and dispositional belief. Turri takes his case to show that an agent can see that $\mathrm{p}$ but not believe that $\mathrm{p}$. But all that it seems to show is that the agent can see that $\mathrm{p}$ without having the occurrent belief that $\mathrm{p}$; it is still an open question as to whether or not the agent can see that $\mathrm{p}$ and lack even the dispositional belief that p. In what follows, I will defend the thesis that the agent lacks the occurent belief that the lines are of unequal length, but possesses the dispositional belief that the lines are of unequal length. The argument can be applied, mutatis mutandis, to the other examples as well. The upshot of this argument is that insofar as propositional knowledge entails dispositional belief and not occurrent belief, the Argument from Belief will be, at best, inconclusive. 


\subsection{Dissipating the argument from belief}

We have seen that there are two general problems facing the Argument from Belief. The first problem was that there seems to be a gap in showing that the sentence or utterance ' $\mathrm{S}$ saw that $\mathrm{p}$, but did not believe that $\mathrm{p}$ ' is intelligible to its being indefeasible evidence of it not being a contradiction. The second problem was the Argument from Belief puts at least as much pressure on the thesis that propositional knowledge entails propositional belief as it does on the thesis that propositional perception entails propositional knowledge. The crucial premise of the Argument from Belief can be used to argue against the Entailment Thesis just as well as it can be used to argued against the thesis that propositional knowledge entails propositional belief. In this fashion, the Argument from Belief is not an effective argument against the Entailment Thesis. But as I mentioned in the previous section, the proponent of the Entailment Thesis should not let the Entailment Thesis hinge on these two considerations alone. There is another, perhaps more fundamental concerns that the proponent of the Entailment Thesis can raise against the Argument from Belief. In this section, I explore these concerns.

Let me be explicit about where the Argument from Belief goes wrong. First, Turri, our token proponent of the Argument from Belief, does not respect the putative distinction between occurrent belief and dispositional belief. ${ }^{23}$ Having an occurrent belief that $\mathrm{p}$ is the mental analogue of assertion-what is sometimes called judgment - or otherwise an occurrent endorsement of the content of a sentence or assertion. So to have the occurrent belief that $\mathrm{p}$ is to actively endorse the content $\mathrm{p}$; it is, roughly, to bring the proposition that $\mathrm{p}$ before one's mind and endorse it. But dispositional belief is not like this. A dispositional belief is, first and foremost, a disposition. If we dispositionally believe that $\mathrm{p}$, and our disposition is triggered, we will manifest our disposition by occurrently believing that $\mathrm{p}$. Dispositional beliefs have two conditions, a 'triggering condition' and a 'manifestation condition'. For example, a fragile glass has the disposition to shatter when struck (the triggering condition), but it can fail to shatter-it can fail to manifest that disposition, failing to meet the manifestation condition-because of a 'mask'. What 'masks' the disposition is the soft packaging (Johnston 1992, p. 223). Likewise, I can have the disposition to actively endorse the content that the lines are of unequal length if I see a pair of lines which look to be of unequal length (a triggering condition), and nevertheless fail to manifest that disposition, because I know that most pairs of lines with that distinctive character are illusory. If we have the amount of knowledge that we think that we have, then most of our beliefs are dispositional and not occurrent. A person can attribute to me a number of beliefs that I have, and it can be true that I have those beliefs, even though I am not at present occurrently believing those attributed propositions. Mathematical propositions are a case in point. I believe that $1+1=2$, that $1+2=3$, that $1+3=4$, that $1+4=5$, and so on. If someone attributes to me the belief-indeed, the knowledge-

23 Cf. Campbell (1967), Audi (1994), and Schwitzgebel (2010) for this distinction. For the literature on whether or not knowledge entails occurrent belief or acceptance, see: Armstrong (1969), Black (1971), and Radford (1970, 1990). 
that $1+9,999=10,000$, it does not follow that I then and there possess the occurrent belief that $1+9,999=10,000$.

Now that we have at least a working distinction between occurrent and dispositional belief, we should ask whether or not Turri and Pritchard's respective examples provide adequate support for the thesis that $S$ can see that $\mathrm{p}$ and nevertheless not have the dispositional belief that $\mathrm{p}$. After all, what seems to be the case is that if $\mathrm{S}$ knows that $\mathrm{p}$, then $\mathrm{S}$ has the dispositional belief that $\mathrm{p}$, and need not have the occurrent belief that p. So, while the Argument from Belief can be expressed as:

(Knowledge Entails Belief) If $\mathrm{S}$ knows that $\mathrm{p}, \mathrm{S}$ believes that $\mathrm{p}$.

(Belief Premise) $\mathrm{S}$ can see that $\mathrm{p}$ and not believe that $\mathrm{p}$.

$\therefore \sim($ Entailment Thesis) $\mathrm{S}$ can see that $\mathrm{p}$ and not believe that $\mathrm{p}$.

We can justifiably question the first premise. It is ambiguous between:

(Knowledge Entails Occurrent Belief) If $\mathrm{S}$ knows that $\mathrm{p}, \mathrm{S}$ possesses the occurrent belief that $\mathrm{p}$.

And the second principle that:

(Knowledge Entails Dispositional Belief) If $\mathrm{S}$ knows that $\mathrm{p}, \mathrm{S}$ has the dispositional belief that $\mathrm{p}$.

Let us consider the first disambiguation of that premise in the following modified Argument from Belief:

(Knowledge Entails Occurent Belief) If S knows that p, S has the occurrent belief that $\mathrm{p}$.

(Occurrent Belief Premise) S can see that $\mathrm{p}$ and not have the occurrent belief that $\mathrm{p}$.

$\therefore \sim($ Entailment Thesis) $\mathrm{S}$ can see that $\mathrm{p}$ and not know that $\mathrm{p}$.

This argument is valid, but it is not sound. The first premise is false or else we lack most of our propositional knowledge. The second premise is true, but uninteresting. $\mathrm{S}$ can see that $\mathrm{p}$ (the lines are of unequal length; a barn is in front of him; a giant mechanical rabbit is in front of him), and not at that time possess the occurrent belief that $\mathrm{p}$. On the other hand, we can construe the argument so that it reads:

(Knowledge Entails Dispositional Belief) If $\mathrm{S}$ knows that $\mathrm{p}, \mathrm{S}$ has the dispositional belief that $\mathrm{p}$.

(Dispositional Belief Premise) S can see that $\mathrm{p}$ and not have the dispositional belief that $\mathrm{p}$.

$\therefore \sim($ Entailment Thesis) $\mathrm{S}$ can see that $\mathrm{p}$ and not know that $\mathrm{p}$.

This argument is valid, but it too is not sound. The first premise is true, but the second premise is false. On the one hand, no proponent of the Argument from Belief has provided adequate support for the second premise (recall Turri and Pritchard); their arguments just do not speak against our seeing that $\mathrm{p}$ and lacking the dispositional belief that $\mathrm{p}$. On the other hand, it is hard to even make sense of the idea that one can see that $\mathrm{p}$ and not have the dispositional belief that $\mathrm{p}$. What would it be for me to see that $\mathrm{o}$ is $\mathrm{F}$ and at the same time not have a disposition to form the occurrent belief that $\mathrm{o}$ is $\mathrm{F}$, 
given certain triggering conditions? At a minimum, the distinction between objectual perception and propositional perception-seeing an o which is F versus seeing that $o$ is $\mathrm{F}$-is grounded in the fact that the latter, but not the former, requires the possession of the concepts $<\mathrm{O}>$ and $<\mathrm{F}>$ and the predicational capacities required to predicate $<\mathrm{F}>$ of $<\mathrm{O}>$. We can wonder how it is even possible for one to see that o is $\mathrm{F}$, and so predicate of $\langle\mathrm{O}\rangle$ that it is $\langle\mathrm{F}\rangle$, while at the same time lacking the dispositional belief that $\mathrm{o}$ is $\mathrm{F}$, given certain triggering conditions. It would be not just interesting, but shocking, to learn that while we see that such and such is so, we can do so even if we lack dispositional beliefs about what we see to be so. Thus far, no such argument has been mounted, nor does it look like an argument could successfully be mounted.

The question I want to ask now is whether or not Turri has shown that the agent lacks occurent belief and dispositional belief, or just lacks occurrent belief. To see how the distinction between occurrent and dispositional belief can help us to dissipate the Argument from Belief, consider what the proponent of the Argument from Belief might think about propositional perception. She might think that even if seeing that $p$ does not entail knowing that $\mathrm{p}$, seeing that $\mathrm{p}$ can still have epistemological implications that mere objectual perception does not have. For example, even if we do not accept the Entailment Thesis, we can consistently accept the following thesis:

(WEAK ENTAILMENT THESIS) If $S$ sees that $p$, then if $S$ knows that $p, S$ believes that $\mathrm{p}$ on the basis of seeing that $\mathrm{p}$.

What might lead epistemologists to accept the weak Entailment Thesis are cases which make it look like $S$ can see that $\mathrm{p}$ and not believe that $\mathrm{p}$ or otherwise believe that $\sim \mathrm{p}$. If the distinction between propositional perception and objectual perception is a good one, we might still think that propositional perception has epistemic implications that mere objectual perception does not have. For example, seeing that $\mathrm{p}$ puts one is a position to know that $\mathrm{p}$, provided that the agent's actual epistemic basis in support of their belief that $\mathrm{p}$ is their having seen that $\mathrm{p}$. But coming to believe that $\mathrm{p}$ is up to the agent; she might do what she ought to do and refrain from believing that $\mathrm{p}$ because she thinks that things are not as she sees them to be. But in such cases what seems to be lacking is not belief simpliciter, but occurrent belief. The proponent of the Entailment Thesis can concede that in such cases it is clear that the agent does not have the occurrent belief that $\mathrm{p}$, and instead maintain that she has the dispositional belief that $\mathrm{p}$. But does $\mathrm{S}$ have the dispositional belief that the lines are of unequal length? It seems so. After all, the capacities that allow him to see that the lines are of unequal length are the same capacities which would allow him to get the occurrent belief that the lines are of unequal length. In seeing that the lines are of unequal length, S manifests those capacities. It is because $\mathrm{S}$ knows that lines which have that distinctive character are often lines of equal length, despite contrary appearances, that explains why he refrains from manifesting his capacity to know that the lines are unequal in length by refraining from believing, in this special case, that it is one in which how things look are how things are. We might put the point as follows. The triggering condition for believing that o is $\mathrm{F}$ (the lines are unequal) is present, since it looks to him as if the two lines are of unequal length. But the manifestation condition is not fulfilled because it is 'masked'. What masks the manifestation of the occurrent belief is his knowledge that two lines with that distinctive character are lines which, although they 
appear to be unequal in length, are nevertheless lines of the same length; this is what explains the ease with which he seems to recognize them as a familiar illusion. So, it is not the case, or at least not obviously the case, that he does not believe that the lines are of unequal length. Instead, it is plausible that he fails to occurrently believe that the lines are of unequal length, although he dispositionally believes that they are. $\mathrm{He}$, therefore, knew right then and there that the lines were of unequal length, due in part to the fortunate circumstances he happened to be in, rather than the unfortunate circumstances he occurrently believed himself to be in.

One potential issue facing this diagnosis of the Argument from Belief is that it seems to have the consequence that $\mathrm{S}$ knew that the lines were of unequal length because he saw that the lines were of unequal length and had the dispositional belief that the lines were of unequal length. I want to concede that this is so. We can make sense of the idea that $\mathrm{S}$ knew that the lines are unequal in length. But it does not follow from that that it would be appropriate for $S$ to assert that he knows that the lines are of unequal length. What explains the impropriety of the assertion that 'I know that the lines are of unequal length' is his occurrent belief that the lines are not of unequal length. Even if the case is modified to show that $\mathrm{S}$ withholds occurrent belief that the lines are of equal length (as the lines appear to be), this is still compatible with $\mathrm{S}$ nevertheless having the dispositional belief that the lines are of unequal length. Indeed, the possession of the dispositional belief is what seems to explain the ease with which $\mathrm{S}$ recognizes that, although the lines appear to be unequal, it is just an illusion.

\section{Concluding remarks}

I have argued that three kinds of argument against the Entailment Thesis are not successful. The Argument from Luck is unsound; the Argument from Defeat is either unsound or its soundness depends on the soundness of the Argument from Belief; and the Argument from Belief is at best inconclusive and at worst fallacious. There might be other considerations against the Entailment Thesis, but the three types of epistemological considerations I reviewed here don't seem to render the Entailment Thesis indefensible.

Acknowledgments I would like to thank Duncan Pritchard, Allan Hazlett, the Edinburgh Epistemology Research Group, and the Editors of Synthese for comments and suggestions on earlier versions of this paper. I would also like to thank Barry Stroud for helpful discussion on the issues I raised in this paper. I am especially indebted to Craig French, whose detailed and insightful comments on an early version of this paper helped improve it substantially.

\section{References}

Armstrong, D. (1969). Does knowledge entail belief? Proceedings of the Aristotelian Society, 70, 21-36. Audi, R. (1994). Dispositional beliefs and dispositions to believe. Nous, 28, 419-434.

Black, C. (1971). Knowledge without belief. Analysis, 31, 152-158.

Campbell, C. A. (1967). Towards a definition of belief. The Philosophical Quarterly, 17, 204-220.

Cassam, Q. (2007a). Ways of knowing. Proceedings of the Aristotelian Society, 107, 339-358.

Cassam, Q. (2007b). The possibility of knowledge. Oxford: Oxford University Press. 
Cassam, Q. (2008). Knowledge, perception, and analysis. South African Journal of Philosophy, 27(3), 36-48.

Cassam, Q. (2009). Knowing and seeing: Responding to Stroud's dilemma. European Journal of Philosophy, 17(4), 571-589.

Dancy, J. (1985). Introduction to contemporary epistemology. Oxford: Wiley.

Dretske, F. (1969). Seeing and knowing. Chicago: University Of Chicago Press.

Dretske, F. (1971). Conclusive reasons. Australasian Journal of Philosophy, 49, 1-22.

Dretske, F. (2010). Self-profile. In J. Dancy, E. Sosa, \& M. Steup (Eds.), A companion to epistemology (2nd ed.). Chichester: Wiley-Blackwell.

Engel, Jr., M. (1992). Is epistemic luck compatible with knowledge? Southern Journal of Philosophy, 30, 59-75.

Engel, Jr., M. (2011). Epistemic luck. Internet Encyclopedia of Philosophy. http://www.iep.utm.edu/ epi-luck/

French, C. (2012). Does propositional seeing entail propositional knowledge? Theoria, 78(2), 115-127.

French, C. (2013). Perceptual experience and seeing that P. Synthese, 190(10), 1735-1751.

Gettier, E. (1963). Is justified true belief knowledge? Analysis, 23(6), 121-123.

Gisborne, N. (2010). The event structure of perception verbs. Oxford: Oxford University Press.

Goldman, A. (1976). Discrimination and perceptual knowledge. Journal of Philosophy, 73, 771-791.

Greco, J. (2003). Knowledge as credit for true belief. In M. DuPaul \& L. Zagzebski (Eds.), Intellectual virtue: Perspectives from ethics and epistemology (pp. 111-134) Oxford: Oxford University Press.

Hiller, A., \& Neta, R. (2007). Safety and epistemic luck. Synthese, 158, 303-313.

Johnston, M. (1992). How to speak of the colors. Philosophical Studies, 68, 221-263.

Lackey, J. (2008). What luck is not. Australasian Journal of Philosophy, 86(2), 255-267.

McDowell, J. (1994). Mind and world. Cambridge, MA: Harvard University Press.

McDowell, J. (2002). Responses. In N. H. Smith (Ed.), Reading McDowell on mind and world (pp. 269305). London: Routledge.

McDowell, J. (2008). The disjunctive conception of experience as material for a transcendental argument. In A. Haddock \& F. Macpherson (Eds.), Disjunctivism: Perception, action, knowledge. Oxford: Oxford University Press.

Millar, A. (2008). Perceptual-recognitional abilities and perceptual knowledge. In A. Haddock \& F. Macpherson (Eds.), Disjunctivism: Perception, action, knowledge. Oxford: Oxford University Press.

Nozick, R. (1981). Philosophical explanations. Cambridge, MA: Harvard University Press.

Peacocke, C. (2005). Another "I": Representing conscious states, perception and others. In J. Bermúdez (Ed.), Thought, reference, and experience: Themes from the philosophy of Gareth Evans. Oxford: Oxford University Press.

Prichard, H. A. (1950). Knowledge and perception. Oxford: Oxford University Press.

Pritchard, D. (2004). Epistemic luck. Journal of Philosophical Research, 29, 193-222.

Pritchard, D. (2005). Epistemic luck. Oxford: Oxford University Press.

Pritchard, D. (2007). Anti-luck epistemology. Synthese, 158, 277-297.

Pritchard, D. (2008). Sensitivity, safety, and anti-luck epistemology. In J. Greco (Ed.), The Oxford handbook of skepticism (pp. 437-455). Oxford: Oxford University Press.

Pritchard, D. (2011). Epistemological disjunctivism and the basis problem. Philosophical Issues (supplement to Nous), 21, 434-455.

Pritchard, D. (2012). Epistemological disjunctivism. Oxford: Oxford University Press.

Pritchard, D. (2013). There cannot be lucky knowledge. In M. Steup, J. Turri \& E. Sosa (Eds.), Contemporary debates in epistemology (2nd ed.). Blackwell.

Radford, C. (1966). Knowledge-By examples. Analysis, 27, 1-11.

Radford, C. (1970). Does unwitting knowledge entail unconscious belief? Analysis, 30, 103-107.

Schwitzgebel, E. (2010). Acting contrary to our professed beliefs, or the gulf between occurrent judgment and dispositional belief. Pacific Philosophical Quarterly, 91, 531-553.

Sosa, E. (1999). How to defeat opposition to Moore. Philosophical Perspectives, 13, 141-154.

Sosa, E. (2007). A virtue epistemology: Apt belief and reflective knowledge (Vol. 1). Oxford: Oxford University Press.

Sosa, E. (2008). Skepticism and perceptual knowledge. In Q. Smith (Ed.), Epistemology: New essays. Oxford : Oxford University Press.

Strawson, P. F. (1992). Analysis and metaphysics: An introduction to philosophy. Oxford: Oxford University Press. 
Strawson, P. F. (1995). My philosophy. In P. Sen \& R. Verma (Eds.), The philosophy of P. F. Strawson. New Delhi: Indian Council of Philosophical Research.

Stroud, B. (2002). Sense-experience and the grounding of thought. In Reading McDowell: On mind and world: New York: Routledge.

Stroud, B. (2009). Scepticism and the senses. European Journal of Philosophy, 17(4), 559-570.

Stroud, B. (2011). Seeing what is so. In J. Roessler, H. Lerman, \& N. Eilan (Eds.), Perception, causation, and objectivity. Oxford: Oxford University Press.

Turri, J. (2010). Does perceiving entail knowing? Theoria, 76(3), 197-206.

Unger, P. (1968). An analysis of factual knowledge. Journal of Philosophy, 65, 157-170.

Unger, P. (1972). Propositional verbs and knowledge. Journal of Philosophy, 64(11), 301-312.

Vogel, J. (2007). Subjunctivitus. Philosophical Studies, 134(1), 73-88.

Williamson, T. (2000). Knowledge and its limits. Oxford: Oxford University Press.

Woozley, A. D. (1953). Knowing and not knowing. Proceedings of the Aristotelian Society, 53, 151-172. 